\title{
Addressing the Challenge of Cultivars Identification and Authentication in Mediterranean Olive Collections: A Case Study in Morocco
}

\author{
El Bakkali Ahmed, \\ Mekkaoui Abderrahman,
}

INRA, UR Amélioration des Plantes et Conservation des Ressources

Phytogénétiques, Meknès, Morocco

El Iraqui El Houssaini Salma, INRA, UR Protection des Plantes, Meknès, Morocco

Essarioui Adil,

INRA, UR système oasiens, Errachidia, Morocco

\section{Khadari Bouchaib,}

AGAP, University Montpellier, CIRAD, INRA, Montpellier SupAgro,

Montpellier, France

Conservatoire Botanique National Méditerranéen de Porquerolles

(CBNMed), UMR AGAP, Montpellier, France

Doi:10.19044/esj.2020.v16n6p339 ～URL:http://dx.doi.org/10.19044/esj.2020.v16n6p339

\begin{abstract}
Conservation and use of well-characterized olive (Olea europaea L.) genetic resources are the key to future olive improvement and sustainable production. Yet, authentication of plant materials in ex-situ olive collections throughout the world has received little attention. Here we characterized 95 accessions, from a collection maintained in the experimental station of INRAMeknes, Morocco, by comparing their SSR (14 markers) and morphological (11 endocarp traits) profiles to an international reference dataset with 672 distinct genotypes corresponding to 535 well-described olive cultivars from the two Worldwide Olive Germplasm Banks of Marrakech, Morocco, and Cordoba, Spain (WOGB-M/C). Results revealed 122 alleles in the Meknes collection versus 265 in the reference database, but the difference was not significant. Additionally, forty cultivars were identified in Meknes collection, among which 33 were present in the reference database. Principal Coordinates Analysis revealed that these varieties span the range of all of the 535 varieties in the international database, indicating important genetic diversity within the investigated plant materials. Finally, cases of mislabeling errors, synonyms, and redundant genotypes pertaining mainly to "Picholine marocaine" and
\end{abstract}


"Frantoio" varieties have been encountered in Meknes collection. Overall, our work highlights the power of coupling modern genetic and morphological tools along with exploring reference databases for authenticating genetic cultivars in olive tree collections.

Keywords: Olea europaea L., Simple sequence repeats (SSR), Meknes olive collection, Worldwide Olive Germplasm Banks (WOGB), Olive database

\section{Introduction}

Olive tree (Olea europaea L.) is a major agricultural crop in the Mediterranean basin with approximately $95 \%$ of the world's olive production (IOOC, 2016), used mostly for oil extraction and canning. Domestication of olive tree in the Mediterranean has taken place over more than 6,000 years through mass selection and clonal propagation (Kaniewski et al., 2012). This has led to the selection of a wide range of cultivars. Specifically, more than 1,200 varieties have been reported in 54 countries and are preserved for conservation and research purposes in nearly 100 distinct collections throughout the globe (Bartolini, 2008). Because of clonal propagation, olive tree has been disseminated greatly across the Mediterranean basin, which resulted in many cases of synonymy (different names for the same cultivar; Barranco et al., 2000), homonymy (same name for different cultivars; Barranco et al., 2005) and molecular variants (intra-varietal variation; Cipriani et al., 2002; Khadari et al., 2008; El Bakkali et al., 2013a). Additionally, mislabeling errors that occurred in the process of establishing germplasm collections have added to the complexity of plant material management (Trujillo et al., 2014; El Bakkali et al., 2019). These issues emphasize the significance of cultivar identification to enhancing our ability for precise classification and authentication of cultivars. Indeed, several studies highlighted the importance of using Simple Sequence Repeats molecular markers (SSR) in characterizing germplasm collections through the exploration of genetic diversity (Sarri et al., 2006; Khadari et al., 2008; Baldoni et al., 2009; Haouane et al., 2011; Belaj et al., 2012; Diez et al., 2012; El Bakkali et al., 2013b; Trujillo et al., 2014). Perhaps more importantly, endocarp traits, being strong discriminative morphological characteristics, have also been described as a powerful complementary tool to molecular techniques that allow increasing identification resolution at the intra-varietal variation level (Belaj et al., 2012; Trujillo et al., 2014; El Bakkali et al., 2019). SSR markers and endocarp traits were routinely used to scrutinize olive germplasm preserved in the two largest worldwide olive germplasm banks (WOGB) in Marrakech-Morocco (Haouane et al., 2011; El Bakkali et al., 2013b) and Cordoba-Spain (Belaj et al., 2012; Diez et al., 2012, Trujillo et al., 2014). Recently, an attempt was conducted to establish one single database by 
characterizing and comparing the 1,091 olive accessions from 22 countries in the two WOGB-M/C collections using 20 SSR markers and 11 endocarps traits (El Bakkali et al., 2019). This collaborative effort identified a total of 672 distinct genotypes, corresponding to 535 well-characterized cultivars, in which 211 cultivars were authenticated. The available database of 672 distinct genotypes provides comparable information about Mediterranean olive germplasm and can serve as a repository data for research on the identification of cultivars and management of olive accessions in local and regional collections throughout the Mediterranean basin. Nonetheless, this database needs enrichment over time for a more extensive referential on olive genetic resources.

In addition to the genetic material preserved in the WOGB of Marrakech, Morocco has another ex-situ large collection of olive germplasm maintained in the experimental station of the National Institute for Agricultural Research (INRA) in the Meknes region (long. 33.931031; lat. 5.274508). This valuable collection has remained poorly explored since its establishment in the fifties (CND, 1955), and recently underwent a rejuvenation process through cutting transplantation with a high risk of mislabeling errors. Such constraints impede the potential of its exploitation as an-yet untapped resource for advancing breeding programs. In this investigation, we build up on previous results from the work carried out on the two WOGBs of Marrakech and Cordoba to characterize the Meknes collection using SSR markers and endocarp traits. Specifically, the objective of this study is to perform accurate identification of accessions and unravel mislabeling errors in the collection to construct a more comprehensive understanding of olive genetic diversity in Morocco and the Mediterranean. This study emphasizes the importance of the use of a comprehensive database to identify and authenticate olive varieties towards use in breeding programs.

\section{Materials \& Methods}

\section{Plant material and SSR genotyping}

Ninety five olive trees from the Meknes collection corresponding to 83 accessions and 79 denominations from 9 countries were used in this study (Table 1). For each individual tree, total DNA was extracted from $1 \mathrm{~g}$ of young leave tissue as described by Khadari et al. (2008). DNA was quality-checked using $0.8 \%$ agarose gel electrophoresis and quantified by spectrofluorometry (GENios Plus, TECAN, Grödig, Austria). Fourteen SSR loci (Table 2) were PCR-amplified in the same conditions as described by El Bakkali et al. (2019). These markers were selected based on their clear amplification, high polymorphism and reproducibility as observed previously by many authors (Baldoni et al., 2009; Haouane et al., 2011; El Bakkali et al., 2013b \& 2019; Trujillo et al., 2014). PCR products were separated using an automatic 
capillary sequencer (ABI prism 3130XL Genetic Analyzer Applied Biosystems, Foster City, CA, USA), using GeneScan 400 HD-Rox as internal standard, and chromatograms were then visualized and analyzed with GeneMapper 3.7 software (Applied Biosystems). The generated dataset was compared to a reference database of 672 genotypes identified from the two WOGB-M/C collections (El Bakkali et al., 2019).

Table 1. List of the accessions in Meknes collection with their codes, origins, corresponding cultivar names and main cultivation areas

\begin{tabular}{|c|c|c|c|c|c|c|}
\hline & $\begin{array}{l}\text { Code in } \\
\text { collection }\end{array}$ & Accession name & Origin & Cultivar name & Origin & Comment \\
\hline 1 & MEK025 & Alfafara & Spain & Picholine marocaine & Morocco & Mislabelling \\
\hline 2 & MEK015 & Amellau & France & Amellau & France & \\
\hline 3 & MEK028 & Americana & Italy & Frantoio & Italy & Mislabelling \\
\hline 4 & MEK070 & Arbequina & Spain & Arbequina-70 & Spain & Mislabelling \\
\hline 5 & MEK0V3 & Arbequina & Spain & Arbequina & Spain & \\
\hline 6 & MEK0V7 & Ayvalik & Turkey & Leccino & Italy & Mislabelling \\
\hline 7 & MEK005(1) & Azeradji & Algeria & Azeradji-005 & Algeria & Mislabelling \\
\hline 8 & MEK005(2) & Azeradji & Algeria & Morisca & Italy & Mislabelling \\
\hline 9 & MEK026 & Barouni du Nord & Tunisia & Lechin de Sevilla & Spain & Mislabelling \\
\hline 10 & MEK073(1) & Blanqueta & Spain & Blanqueta & Spain & \\
\hline 11 & MEK073(2) & Blanqueta & Spain & Blanqueta & Spain & \\
\hline 12 & MEK068 & Blanquette De Gastu & Algeria & Chetoui & Tunisia & $\begin{array}{l}\text { Molecular variant and synonyme } \\
\text { of Chetoui (Cimato and Attilio, } \\
\text { 2003; El Bakkali et al., 2019) }\end{array}$ \\
\hline 13 & MEK074(1) & Blanquette de Guelma & Algeria & Picholine marocaine & Morocco & Mislabelling \\
\hline 14 & MEK074(2) & Blanquette de Guelma & Algeria & Picholine marocaine & Morocco & Mislabelling \\
\hline 15 & MEK004 & Bouchouk Soummam & Algeria & Azeradj & Algeria & $\begin{array}{l}\text { Synonymous of Azeradji (El } \\
\text { Bakkali et al., 2019) }\end{array}$ \\
\hline 16 & MEK035(1) & Canino & Italy & Ascolana tenera & Italy & Mislabelling \\
\hline 17 & MEK035(2) & Canino & Italy & Picholine marocaine & Morocco & Mislabelling \\
\hline 18 & MEK051 & Carboncella & Italy & Craputea & Italy & Mislabelling \\
\hline 19 & MEK029 & Carmelitana & Italy & Frantoio & Italy & Mislabelling \\
\hline 20 & MEK016 & Castellana & Spain & Picholine marocaine & Morocco & Mislabelling \\
\hline 21 & MEK067 & Cellina Di Nardo & Italy & Blanqueta & Spain & Mislabelling \\
\hline 22 & MEK024(1) & Changlot Real & Spain & Changlot Real & Spain & \\
\hline 23 & MEK024(2) & Changlot Real & Spain & Ogliarola del Bradano & Italy & Mislabelling \\
\hline 24 & MEK071(1) & Chemlal De Kabylie & Algeria & Chetoui & Tunisia & Mislabelling \\
\hline 25 & MEK071(2) & Chemlal De Kabylie & Algeria & Chetoui & Tunisia & Mislabelling \\
\hline 26 & MEK0V9 & Chemlal De Kabylie & Algeria & Picholine marocaine & Morocco & Mislabelling \\
\hline 27 & MEK077 & Chemlali de Nord & Tunisia & Arbequina & Spain & $\begin{array}{l}\text { Synonymous of Arbequine } \\
\text { (El Bakkali et al., 2019) }\end{array}$ \\
\hline 28 & MEK078 & Chemlali de Sfax & Tunisia & Picholine marocaine & Morocco & Mislabelling \\
\hline 29 & MEK072 & Chetoui & Tunisia & Blanqueta & Spain & Mislabelling \\
\hline 30 & MEK076(1) & Chetoui & Tunisia & Frantoio & Italy & Mislabelling \\
\hline 31 & MEK076(2) & Chetoui & Tunisia & Frantoio & Italy & Mislabelling \\
\hline 32 & MEK030 & Coratina & Italy & Coratina & Italy & \\
\hline 33 & MEK002 & Cordovil de Serpa & Portugal & Madural & Portugal & $\begin{array}{l}\text { Synonymous of Madural (Bracci, } \\
1937 \text {; Trujillo et al., } 1995 \text { and } \\
2014 \text {; El Bakkali et al., 2019) }\end{array}$ \\
\hline 34 & MEK007(1) & Cornicabra & Spain & Cornicabra & Spain & Molecular variant of Cornicabra \\
\hline 35 & MEK007(2) & Cornicabra & Spain & Picholine marocaine & Morocco & Mislabelling \\
\hline 36 & MEK066 & Correggiolo & Italy & Correggiolo-66 & Italy & Mislabelling \\
\hline 37 & MEK023 & Dolce Del Morocco & Italy & Americano & Italy & Mislabelling \\
\hline 38 & MEK061 & Dritta di Moscufo & Italy & Dritta di Moscufo & Italy & \\
\hline 39 & MEK014 & Du Tell & Algeria & Picholine marocaine & Morocco & Synonymous of Picholine \\
\hline
\end{tabular}




\begin{tabular}{|c|c|c|c|c|c|c|}
\hline 40 & MEK065 & Frantoio & Italy & Frantoio & Italy & \\
\hline 41 & MEK010 & Galega & Portugal & Galega vulgar & Portugal & Molecular variant of Galega \\
\hline 42 & MEK019 & Galega D'Elvas & Portugal & Galega vulgar & Portugal & Synonymous of Galega Vulgar \\
\hline 43 & MEK001 & Galega Grada & Portugal & Madural & Portugal & Mislabelling \\
\hline 44 & MEK045 & Ghiandaro & Italy & Ghiandaro & Italy & \\
\hline 45 & MEK033 & Grappolo & Italy & Grappolo-33 & Italy & Mislabelling \\
\hline 46 & MEK044 & Grossa de Sicilia & Italy & Passulunara & Italy & $\begin{array}{l}\text { Possible synonymous of } \\
\text { Passulunara }\end{array}$ \\
\hline 47 & MEK008 & Hojiblanca & Spain & Ocal & Spain & Mislabelling \\
\hline 48 & MEK055 & Lavagnina & Italy & Frantoio & Italy & $\begin{array}{l}\text { Molecular variant and possible } \\
\text { synonymous of Frantoio }\end{array}$ \\
\hline 49 & MEK059(2) & Leccino & Italy & Picholine marocaine & Morocco & Mislabelling \\
\hline 50 & MEK059(1) & Leccino & Italy & Leccino & Italy & \\
\hline 51 & MEK009 & Leucocarpa & Italy & Leucocarpa & Italy & \\
\hline 52 & MEK075 & Limli & Algeria & Picholine marocaine & Morocco & $\begin{array}{l}\text { Synonymous of Picholine } \\
\text { marocaine (El Bakkali et al., 2019) }\end{array}$ \\
\hline 53 & MEK062 & Loretana & Italy & Dritta di Moscufo & Italy & $\begin{array}{l}\text { Synonymous of Dritta di Moscufo } \\
\text { (Barranco et al., 2000) }\end{array}$ \\
\hline 54 & MEK036 & Madonna Dell'Impruneta & Italy & Madonna Dell'Impruneta- & Italy & Mislabelling \\
\hline 55 & MEK011 & Madural & Portugal & Madural & Portugal & \\
\hline 56 & MEK0V11 & Manzanille de Sevilla & Spain & Villalonga & Spain & Mislabelling \\
\hline 57 & MEK006 & Marsalina & Tunisia & Picholine marocaine & Morocco & Mislabelling \\
\hline 58 & MEK053 & Maurino & Italy & Maurino & Italy & \\
\hline 59 & MEK012 & Meslala & Morocco & Meslala & Morocco & \\
\hline 60 & MEK058 & Mignolo & Italy & Americano & Italy & Mislabelling \\
\hline 61 & MEK037(2) & Moraiolo & Italy & Picholine marocaine & Morocco & Mislabelling \\
\hline 62 & MEK037(1) & Moraiolo & Italy & Moraiolo & Italy & \\
\hline 63 & MEK060 & Moraiolo & Italy & Moraiolo & Italy & \\
\hline 64 & MEK056 & Morellona Di Grecia & Italy & Frantoio & Italy & Mislabelling \\
\hline 65 & MEK054 & Morenillo & Italy & Frantoio & Italy & Mislabelling \\
\hline 66 & MEK057 & Nebbio & Italy & Picholine marocaine & Morocco & Mislabelling \\
\hline 67 & MEK046 & Nostrale & Italy & Frantoio & Italy & Mislabelling \\
\hline 68 & MEK027 & Oblonga & USA & Frantoio & Italy & $\begin{array}{l}\text { Synonymous of Frantoio (Trujillo } \\
\text { et al., } 2014 \text {; Muzzalupo et al., } \\
\text { 2014) }\end{array}$ \\
\hline 69 & MEK047 & Ogliarola & Italy & Ogliarola del Bradano & Italy & \\
\hline 70 & MEK050 & Olivella & Italy & Gremigno di Fauglia & Italy & Synonymous Gremigno di Fauglia \\
\hline 71 & MEK022 & Oliviere & France & Picholine marocaine & Morocco & Mislabelling \\
\hline 72 & MEK031 & Piangente & Italy & Piangente & Italy & \\
\hline 73 & MEK0V4 & Picholine marocaine & Morocco & Picholine marocaine & Morocco & \\
\hline 74 & MEK017 & Pigale & France & Picholine marocaine & Morocco & Mislabelling \\
\hline 75 & MEK039 & Pisciottana & Italy & Frantoio & Italy & Mislabelling \\
\hline 76 & MEK034(1) & Racemo & Italy & Picholine marocaine & Morocco & Mislabelling \\
\hline 77 & MEK034(2) & Racemo & Italy & Coratina & Italy & $\begin{array}{l}\text { Synonymous of Coratina } \\
\text { (Muzzalupo et al., 2014) }\end{array}$ \\
\hline 78 & MEK032 & Rama Pendula & Italy & Picholine marocaine & Morocco & Mislabelling \\
\hline 79 & MEK064 & Razzo & Italy & Frantoio & Italy & $\begin{array}{l}\text { Synonumous of Frantoio (Perri et } \\
\text { al., 1999) }\end{array}$ \\
\hline 80 & MEK003(1) & Redondal & Portugal & Ascolana tenera & Italy & Mislabelling \\
\hline 81 & MEK003(2) & Redondal & Portugal & Madural & Portugal & Mislabelling \\
\hline 82 & MEK013 & Ronde de la Menara & Morocco & Ronde de la Menara-13 & Morocco & Mislabelling \\
\hline 83 & MEK052 & Rosciola & Italy & Dritta di Moscufo & Italy & Mislabelling \\
\hline 84 & MEK040 & Rotondella & Italy & Moraiolo & Italy & Mislabelling \\
\hline 85 & MEK069 & Rougette & Algeria & Arbequina & Spain & Mislabelling \\
\hline 86 & MEK063 & Rougette de Pignan & France & Frantoio & Italy & Mislabelling \\
\hline 87 & MEK041 & Sallela & Italy & Gremigno di Fauglia & Italy & $\begin{array}{l}\text { Synonymous of Gremigno di } \\
\text { Fauglia }\end{array}$ \\
\hline 88 & MEK048 & Serrana & Spain & Sevillenca & Spain & $\begin{array}{l}\text { Synonymous of Sevillenca } \\
\text { (Barranco et al., 2000) }\end{array}$ \\
\hline
\end{tabular}




\begin{tabular}{|c|c|c|c|c|c|c|}
\hline 89 & MEK043 & Serranas & Spain & Sevillenca & Spain & Synonymous of Sevillenca \\
\hline 90 & MEK018 & Tabelout & Algeria & Tabelout & Algeria & \\
\hline 91 & MEK049 & Taggiasca & Italy & Taggiasca & Italy & \\
\hline 92 & MEK038 & Teschi & Italy & Picholine marocaine & Morocco & Mislabelling \\
\hline 93 & MEK021 & Verdale & France & Picholine marocaine & Morocco & Mislabelling \\
\hline 94 & MEK020 & Verdial & Portugal & Verdial transmontana & Portugal & \\
\hline 95 & MEK042 & Vernina & Italy & Vernina & Italy & \\
\hline
\end{tabular}

\section{Morphological characterization}

Forty randomly chosen endocarps per tree were characterized independently by two experienced observers over two years (2016 and 2017) following the protocol described by Trujillo et al. (2014). Specifically eleven endocarp traits were used: weight, shape in position A, symmetry in positions $\mathrm{A}$ and $\mathrm{B}$, position of maximum transverse diameter in position $\mathrm{B}$, shape of apex in position $A$, shape of base in position $A$, roughness of surface, number of grooves on basal end, distribution of the grooves on basal end and presence of mucro.

\section{Data analysis}

SSR profiles of the 95 olive trees were compared to 672 distinct genotypes of the reference database of WOGB-M/C using Excel Microsatellite TOOLKIT (Park, 2001). Genetic diversity in each dataset, Meknes collection and WOGB-M/C, was estimated by calculating a set of parameters for each microsatellite locus using Excel Microsatellite ToOLKIT including; allele size, number of alleles $(\mathrm{Na})$, number of unique alleles $(\mathrm{Nu})$, observed (Ho) and expected heterozygosity (He; Nei, 1987) and polymorphism information content (PIC, Botstein et al., 1980). In addition, pairwise comparison among samples within Meknes collection based on endocarp traits was conducted to identify distinct morphological profiles using a binary matrix of different morphological states; 0 : absent and 1: present.

Moreover, phylogenetic relationships among accessions in Meknes collection was revealed by converting SSR data into a binary matrix ( 0 and 1 ) and constructing dendrogram using Dice similarity index (Dice, 1945) and UPGMA method with NTSYS-PC v2.02 software (Rohlf, 1998). Spatial distribution of the genotypes in both Meknes collection and WOGB-M/C was described based on Principal Coordinate Analysis (PCoA) with simple matching coefficient (Sokal and Michener, 1958) using the DARWIN v.5.0.137 program (Perrier et al., 2003).

Finally, comparison between Meknes collection and WOGB-M/C was carried out based on different criteria such as: (i) accessions name, (ii) number of shared genotypes and cultivars, (iii) number of alleles (Na) and Nei diversity index (He) and (iv) allelic richness (Ar, Petit et al., 1998). Allelic richness (Ar) was computed following a generalized rarefaction approach at the standardized $G$ value using the ADZE program (Szpiech et al., 2008). 
Significant differences in rarefied Ar and He were revealed using MannWhitney comparison test ( $p \leq 0.05)$ with PAST program (Hammer et al., 2001).

\section{Results}

\section{Characterization of Meknes collection}

\subsection{SSR polymorphism}

Based on 14 SSR markers, a total of 122 alleles were observed in Meknes collection among which 15 alleles were unique (Table 2). The number of alleles ranged from 4 for DCA15 to 14 for DCA09 with a mean of 8.71 alleles/locus. Index of diversity $(\mathrm{He})$ varied from 0.468 for DCA05 locus to 0.855 for DCA16 locus with an average of 0.699. Twelve markers among the 14 had a PIC value greater than 0.5 . These data indicate significant genetic variability among accessions in the collection.

Table 2. Summary of genetic diversity parameters of 14 SSR markers observed in both Meknes collection and reference database.

\begin{tabular}{|c|c|c|c|c|c|c|c|c|c|c|c|}
\hline \multirow[b]{2}{*}{ SSR Marker } & \multicolumn{6}{|c|}{ Meknes collection } & \multicolumn{5}{|c|}{ Reference database } \\
\hline & $\begin{array}{l}\text { Size } \\
\text { (bp) }\end{array}$ & $\mathbf{N a}$ & $\mathbf{N u}$ & $A \mathbf{r}^{1}$ & He & PIC & $\begin{array}{l}\text { Size } \\
\text { (bp) }\end{array}$ & $\mathbf{N a}$ & $\mathrm{Nu}$ & $A \mathbf{r}^{1}$ & He \\
\hline DCA01 ${ }^{\mathrm{a}}$ & $204-272$ & 7 & 1 & 5.5 & 0.672 & 0.613 & $204-274$ & 21 & 3 & 5.4 & 0.624 \\
\hline DCA03 ${ }^{a}$ & $227-253$ & 9 & & 8.3 & 0.824 & 0.797 & $227-255$ & 15 & & 8.3 & 0.850 \\
\hline DCA04 ${ }^{a}$ & $129-174$ & 9 & 2 & 7.4 & 0.627 & 0.566 & $116-198$ & 35 & 3 & 9.9 & 0.761 \\
\hline DCA05 & $191-211$ & 8 & 1 & 6.9 & 0.468 & 0.443 & $191-213$ & 12 & & 6.8 & 0.443 \\
\hline DCA08 ${ }^{\mathrm{a}}$ & $123-159$ & 13 & 3 & 9.7 & 0.808 & 0.778 & $123-168$ & 23 & 3 & 9.0 & 0.825 \\
\hline DCA09a & $160-214$ & 14 & 2 & 10.6 & 0.826 & 0.800 & $160-218$ & 26 & 2 & 12.3 & 0.873 \\
\hline DCA1 $1^{\mathrm{a}}$ & $126-180$ & 12 & 3 & 8.9 & 0.801 & 0.768 & $126-185$ & 26 & 2 & 10.0 & 0.824 \\
\hline DCA15a & $243-267$ & 4 & & 3.9 & 0.573 & 0.509 & $243-267$ & 7 & 1 & 4.1 & 0.551 \\
\hline DCA16 ${ }^{\mathrm{a}}$ & $122-179$ & 13 & 1 & 10.9 & 0.855 & 0.834 & $122-230$ & 39 & 6 & 10.9 & 0.861 \\
\hline DCA18 ${ }^{\mathrm{a}}$ & $154-180$ & 10 & & 8.5 & 0.812 & 0.781 & $154-193$ & 19 & 3 & 9.2 & 0.824 \\
\hline EMO90 ${ }^{b}$ & $181-193$ & 5 & & 4.7 & 0.642 & 0.583 & $181-208$ & 10 & 1 & 5.9 & 0.659 \\
\hline GAPU59 ${ }^{c}$ & $206-226$ & 6 & & 5.0 & 0.633 & 0.572 & $194-239$ & 13 & 4 & 5.2 & 0.615 \\
\hline GAPU71A $^{c}$ & $207-240$ & 7 & 2 & 5.7 & 0.475 & 0.441 & $206-256$ & 16 & 3 & 4.2 & 0.452 \\
\hline GAPU 71B & $118-141$ & 5 & & 5.0 & 0.780 & 0.739 & $118-147$ & 10 & & 6.0 & 0.803 \\
\hline Mean & & 8.71 & 1.07 & $7.2 *$ & 0.699* & 0.659 & & 19.42 & 2.8 & $7.6^{*}$ & 0.711* \\
\hline Total & & 122 & 15 & 100. & & & & 272 & 31 & 106.4 & \\
\hline
\end{tabular}

Na: Number of alleles, Nu: number of unique alleles, Ar: allelic richness, He: expected heterozygosity, Ho: observed heterozygosity, PIC: polymorphic information content.

${ }^{1}$ Computed at $\mathrm{G}$ value of 42 . No significant difference between both datasets (Mann-Whitney test, $p$-value >0.05). ${ }^{2}$ Shared alleles between both Meknes collection and reference dataset. *Index of significance at p-value $<0.05$.

${ }^{\mathrm{a} S e f c}$ et al. (2000), ${ }^{\mathrm{b}} \mathrm{De}$ La Rosa et al. (2002), ${ }^{\mathrm{c}}$ Carriero et al. (2002).

\subsection{Identification of cultivars using SSR markers and morphological traits}

Based on SSR profiles, the 95 olive trees maintained in the Meknes collection were classified into 42 distinct genotypes (Tables 3 ). The best discriminative markers that allowed differentiation among all accessions are DCA04, DCA09, and DCA16. The 42 identified genotypes were represented 
by 25 accessions with unique SSR profiles and 70 accessions having multiple overlapping SSR profiles that define 17 distinct genotypes.

Endocarp traits-based classification of the Meknes collection accessions yielded virtually similar patterns. In sum, a total of 38 different morphological profiles were identified. The 38 profiles were classified as 22 accessions with unique morphological profiles and 70 accessions sharing core sets of traits that determine 16 morphotypes.

Combined information from SSR markers and endocarp traits differentiates 40 different olive cultivars in Meknes collection (Figure 1; Tables 1 and 3). Only two cases of molecular variants were identified in the collection for "Frantoio" and "Chetoui" cultivars (Figure 1). Overall, these results highlight the crucial role of coupling genetic markers and endocarp characteristics in disentangling differences and similarities among olive tree accessions.

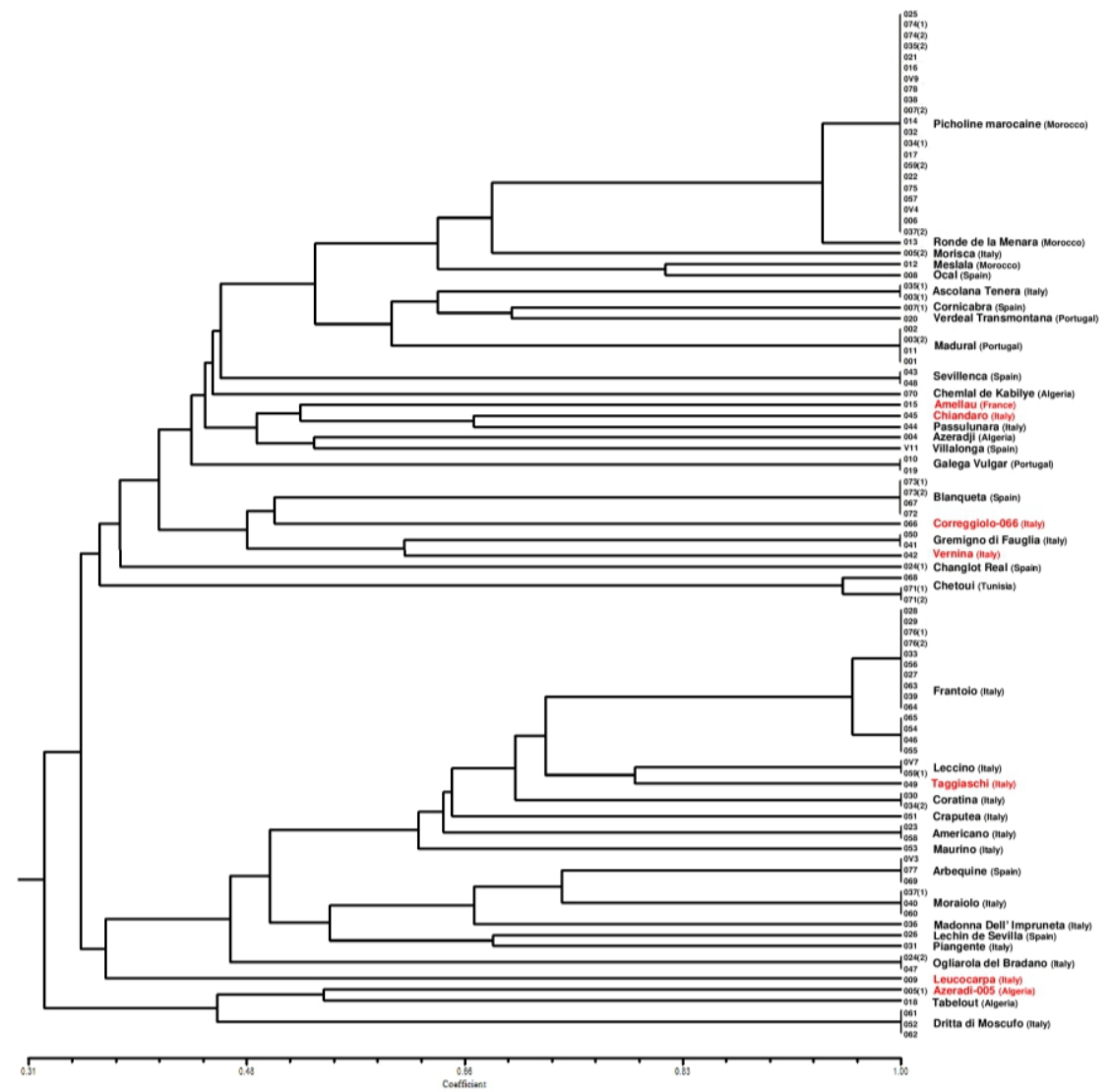

Figure 1. Dendrogram based on UPGMA method and Dice similarity index of the 40 identified cultivars in Meknes collection showing redundant accessions and molecular variants. Numbers indicate the accessions code. Cultivars that are shared with the reference database (black) and those specific to Meknes collection (red) are shown. 
Table 3. Number of olive accession per origin, number of genotypes including variants and identified cultivars in Meknes collection. Number of shared genotypes and cultivars with the reference database are indicated.

\begin{tabular}{cccccc}
\hline & $\begin{array}{c}\text { No. of } \\
\text { trees } \\
\text { analyzed }\end{array}$ & $\begin{array}{c}\text { No. of } \\
\text { accessions }\end{array}$ & $\begin{array}{c}\text { No. of } \\
\text { denomination } \\
()^{\mathbf{1}}\end{array}$ & $\begin{array}{c}\text { No. of } \\
\text { genotypes }\end{array}$ & $\begin{array}{c}\text { No. of } \\
\text { identified } \\
\text { cultivars }^{\mathbf{3}}\end{array}$ \\
\hline Algeria & 13 & 10 & $9(8)$ & $4(3)^{4}$ & $4(3)^{4}$ \\
France & 5 & 5 & $5(2)$ & $1(0)$ & $1(0)$ \\
Italy & 43 & 39 & $38(17)$ & $21(15)$ & $20(15)$ \\
Morocco & 3 & 3 & $3(3)$ & $3(3)$ & $3(3)$ \\
Portugal & 8 & 7 & $7(7)$ & $3(3)$ & $3(3)$ \\
Spain & 14 & 11 & $10(8)$ & $8(8)$ & $8(8)$ \\
Tunisia & 7 & 6 & $5(5)$ & $2(2)$ & $1(1)$ \\
Turkey & 1 & 1 & $1(1)$ & 0 & 0 \\
USA & 1 & 1 & $1(1)$ & 0 & 0 \\
\hline Total & $\mathbf{9 5}$ & $\mathbf{8 3}$ & $\mathbf{7 9}(\mathbf{5 2})$ & $\mathbf{4 2}(\mathbf{3 4})^{\mathbf{4}}$ & $\mathbf{4 0}(\mathbf{3 3})^{\mathbf{4}}$ \\
\hline
\end{tabular}

${ }^{1}$ Number of similar denominations compared to El Bakkali et al. (2019) database. ${ }^{2}$ based on 14 SSR loci only. ${ }^{3}$ based on both SSR loci and endocarp traits. ${ }^{4}$ nomber of shared genotypes and cultivars with the reference database.

\section{Comparison between Meknes collection and WOGB-M/C}

\subsection{Based on accessions' denomination}

Among the 83 accessions in Meknes collection, 79 accessions' names were listed versus 713 denominations among the 1,091 accessions in WOGB$\mathrm{M} / \mathrm{C}$ (Table 1). Fifty two accessions' names were listed in both datasets, whereas 27 labels such as "Canino", "Leucocarpa" and "Vernina" were specific to Meknes collection. Italian germplasm contained the greatest number of shared denomination $(17 ; 32.7 \%)$. Otherwise, common denominations were scattered across genetic materials of different origins and ranged between 1 and 8 denominations respectively for American ("Oblanga") and Turkish ("Ayvalik") and Algerian germplasm (i.e. "Blanquette de Guelma", "Bouchouk Soummam", "Chemlal de Kabylie"...etc.; Table 1).

\subsection{Based on SSR markers and morphological traits}

As per SSR analysis, the combined dataset (42 genotypes from Meknes collection and 672 genotypes from WOGB-M/C) encompassed 272 alleles with a mean of 19.42 alleles/locus. The 2 datasets shared 122 alleles (46\%) including the 15 unique alleles observed in Meknes collection (Table 2). No significant difference between the two datasets was observed in terms of allelic richness, computed at $\mathrm{G}$ value of 42 , or diversity index (He; Mann-Whitney test, p-value > 0.05; Table 2).

There were 34 SSR profiles overlap between Meknes and WOGB-M/C collections and 8 were specific to the former (i.e. "Leucocarpa", "Taggiaschi", "Vernina"...etc.; Table 1; Figure 1). The 34 shared genotypes had 114 
(93.4\%) alleles versus 80 (65\%) alleles in SSR profiles that were specific to Meknes collection (8 genotypes). Principal coordinate analysis explained 14\% of the total genetic variation within the combined dataset and showed that the 42 genotypes of Meknes collection span the range of the genetic diversity contained in the 672 genotypes of WOGB-M/C dataset (Figure 2).

The use of endocarp traits alone decreased resolution in discerning differences among accessions as only 378 different morphological profiles were identified in the whole dataset compared to 680 SSR profiles. Seven olive trees in Meknes collection exhibited unique morphotypes whereas the others shared similarities with accessions of WOGB-M/C database. This resulted in the identification of 31 different morphological profiles in common.

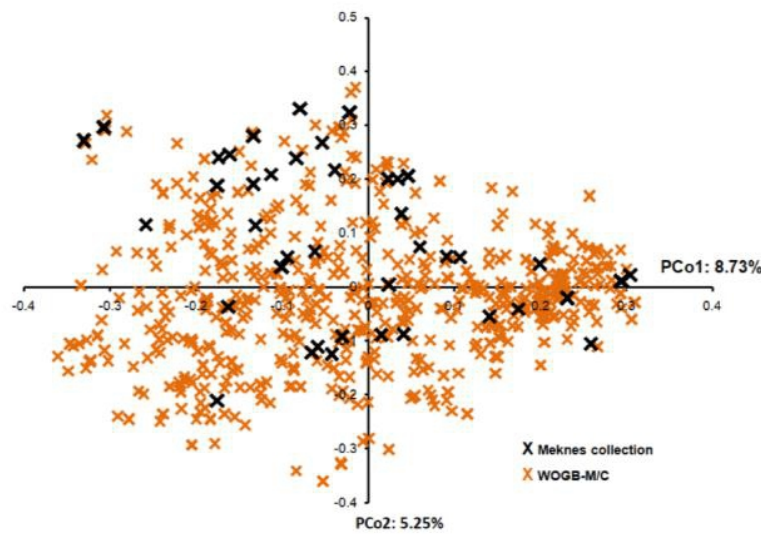

Figure 2. Principal coordinate analysis (PCoA) showing two-dimensional distribution of the genotypes in the two datasets. The first two principal axes account for $13.98 \%$ of the total genetic variation among genotypes. The 42 genotypes identified in Meknes collection span the range of all the genotypes in WOGB-M/C collections.

\section{Cultivars authentication and synonymy detection in Meknes collection}

\subsection{Cultivars authentication}

Using endocarp traits and SSR markers combined, a total of 542 cultivars were identified in the composite dataset with 33 cultivars belonging to both collections (Figure 1). Thus, only 7 cultivars such as "Leucocarpa" from Italy and "Amellau" from France were exclusive to Meknes collection (Figure 1). Though there were mismatches between accession names in Meknes collection and their corresponding putative cultivars in WOGB-M/C, we were able to authenticate the 33 cultivars shared between Meknes and WOGB-M/C as they showed similar SSR and morphological profiles with their counterparts in the latter such as "Picholine marocaine" from Morocco, "Frantoio" from Italy, "Galega Vulgar" from Portugal and "Arbequina" from Spain. However, the 7 cultivars that were specific to Meknes collection (Figure 1) remained unauthenticated and require further studies in this regard. 


\subsection{Plantation mislabeling and Synonymy detection}

Fifty cases of mislabeled plantations were detected in Meknes collection. For instance, based on their profiles, the accessions "Olivière" (MEK022) from France and "Leccino" (MEK059-2) from Italy showed similar profiles to the well-known cultivar "Picholine marocaine". In addition, all of the mislabeled accessions were different from their correspondent cultivars in WOGB-M/C. Interestingly, most of cultivars concerned by labeling errors turned out to belong to "Picholine marocaine" (18 cases) and "Frantoio" (9 cases).

Aside from plantation mislabeling, several synonymy cases were present in Meknes collection. Specifically, there were 17 names used interchangeably for 10 cultivars. While 10 of these had been previously described, seven cases are reported for the first time in this work (Table 1). For instance, in addition to "Limli" that was reported as a synonym of "Picholine marocaine" (El Bakkali et al., 2019), we here found that "Du Tell" from Algeria is synonymous to that cultivar as well. Similarly, besides "Razzo" and "Oblonga" formerly recognized as referring to the cultivar "Frantoio" (El Bakkali et al., 2019), our work adds "Lavagnina" from Italy to this list. Furthermore, no case of homonymy was identified within Meknes collection; all accessions sharing similar name and showing different profiles were noted as mislabeling errors.

\section{Discussion}

Establishment of experimental design of olive species for phenotyping in contrasted environment is a tedious and costly task. As a perennial fruit species with a long juvenile period, the use of available germplasm collections represents an efficient alternative. However, mislabeling plantations compels management of these collections and can thus have potential negative implications on the use of genetic materials in breeding programs. Such issues have been encountered in wide spectrum of other fruit species such as cherimoya (Escribano et al., 2007), apple (Evans et al., 2011) and grape (Riaz et al., 2008). Hence, conducting phenotyping studies using several germplasm collections at a time by mining diversity maintained in different collections could be hindered by the identification and authentication process of varieties. Thus, there is urgent need for standardizing genotyping methods and protocols that lead to compatible outcomes before any use of germplasm.

Efforts have been devoted to genotyping many olive collections all over the world (Khadari et al., 2003; Koehmstedt et al., 2011; Trentacoste et al., 2011; Muzzalupo et al., 2014; Xanthopoulou et al., 2014). However, though virtually the same set of SSR markers were used in these studies, full reproducibility of their results has not always been achieved due to differences in genotyping laboratory conditions (Baldoni et al., 2009). Significant 
international efforts have been made to gather olive germplasm in a single and commun database. The 2008 web-based edition (http://www.oleadb.it/) is currently the largest database with information extracted from almost 1,520 publications and concerned about 1,250 cultivars conserved in over 100 collections in 54 countries (Bartolini, 2008). However, this generated database represents an underestimate level of olive tree diversity, since many minor local cultivars that are specific to olive growing areas such as Morocco, Cyprus, Egypt and Syria, are not included. Taking advantage from the study of Trujillo et al. (2014), an attempt was conducted to establish a large database by gathering and aligning profiles of almost total accessions in the two Worldwide Olive Germplasm Banks of Marrakech, Morocco, and Cordoba, Spain, using 20 common SSR markers and 11 endocarps traits (El Bakkali et al., 2019). The open-access database represents the first most exhaustive genotyping analysis on olive cultivars germplasm conducted so far and considered an efficient tool for the identification of cultivars and management of the olive accessions in local and regional collections throughout the world.

In addition to the WOGBs of Marrakech and Cordoba, other regional and local collections exist which constitute valuable platforms for preserving genetic diversity and use in breeding programs. Regardless of their sizes and locations, effective management of these collections and their exploitation in breeding programs have been constrained by the lack of precise identification of their genetic resources. In this work, we addressed this challenge and showed that the use of a combination of genetic and morphological traits can play a paramount role in the process of olive tree authentication in the collection of Meknes-Morocco. We were able to identify many cases of synonymous and mislabeling errors using both SSR markers and endocarp traits. These findings demonstrate the discriminative power of coupling advanced genetic techniques and precise morphological features in characterizing unauthenticated olive germplasm.

We propose a strategy based on aligning germplasm olive collections with the open-access dataset (WOGB-M/C) to establish a single consensus database. Core cultivars, such as "Picholine marocaine", "Frantoio", "Leccino", "Arbequina" and "Picual" ...etc., largely present in most collections and cultivated around the world could play a capital role in the characterization and varietal identification processes by using them as an anchor to align the true size of alleles while taking advantage of the resolution power and high sensitivity provided by the 6 SSR markers and 11 endocarp traits used in the investigation (El Bakkali et al., 2019).

The identification and authentication of varieties within a given germplasm collection is a prerequisite step before conducting further breeding studies. Taking advantage from the previous study of El Bakkali et al. (2019), we were able to authenticate 33 cultivars, from a total of 40 identified cultivars 
in which 32 are maintained in the WOGB of Marrakech (except "Villalonga" cultivar). The 32 identified cultivars represent an efficient experimental design to study traits of agronomical interest in two contrasted Moroccan sites such as Meknes and Marrakech. This finding is supported by the high genetic diversity detected within these cultivars regarding the similarity index, the insignificant difference of allelic richness, and their spatial distribution that span the range of the 672 genotypes identified in both WOGB of Marrakech and Cordoba as observed by the Principal Coordinate Analysis (Figure 2). Such identified cultivars could be used as experimental design to evaluate agronomical traits in complement to other contrasted environmental conditions and therefore to conduct further studies such as genetic association mapping.

\section{Conclusion}

Conservation of olive genetic resources comes often with the challenge of effective management of ex-situ collections. This may put at stake the ultimate objective of creating these collections. Indeed, synonymous and homonymous cases coupled with mislabeling errors can have downstream tremendous negative impacts on olive production traceability. The study case we present in this work sheds light on this issue and provides strong evidence that comparative genetics and morphologic features with well-characterized referential databases has the potential to unlock the secrets of unauthenticated olive plant materials in ex-situ collections throughout the world.

\section{Acknowledgments}

The authors would like to thank Ch. Tollon and S. Santoni for their kind support in the molecular analysis. All molecular genotyping was performed in the 'Atelier de Marquage Moléculaire' of INRA/SupAgro Montpellier-France. The morphological analysis was conducted at INRAMeknes. This study was supported by the French-Morocco cooperation PHC PRAD 14-03 / Campus France N³0260SD.

\section{References:}

1. Baldoni, L., Cultrera N.G., Mariotti, R., Ricciolini, C., Arcioni, S., Vendramin, G.G., Buonamici, A., Porceddu, A., Sarri, V., Ojeda, M.A., Trujillo, I., Rallo, L. , Belaj, A., Perri, E., Salimonti, A., Muzzalupo, I., Casagrande, A., Lain, O., Messina, R., Testolin, R. (2009). A consensus list of microsatellite markers for olive genotyping. Molecular Breeding 24: 213-231.

2. Barranco, N.D., Cimato, A., Fiorino, P., Rallo, R.L., Touzani, A., Castañeda, C., Serafini, F., Trujillo, I. (2000). World catalogue of olive varieties. Pages: 360. COI, Mundi-Prensa Madrid, Spain. 
3. Barranco, D., Trujillo, I., Rallo, L. (2005). Elaiografía Hispanica. In: Rallo L, Barranco D, Caballero JM, Del Rio C, Martin A, Tous J, Trujillo I (eds) Variedades de olivo en España. Mundi-Prensa, Madrid.

4. Bartolini, G. (2008). Olive Germplasm (Olea europaea L.) (Cultivars, synonyms, cultivation area, collections, descriptors). DOI: 10.7349/OLEA_databases.

5. Belaj, A., Dominguez-García, M.C., Atienza, S.G., Martín Urdíroz, N., De la Rosa, R., Satovic, Z., Martín, A., Kilian, A., Trujillo, I., Valpuesta, V., Del Río, C. (2012). Developing a core collection of olive (Olea europaea $\mathrm{L}$ ) based on molecular markers (DArTs, SSRs, SNPs) and agronomic traits. Tree Genetics \& Genomes 8: 365-378.

6. Bracci, F. (1937). Le varietà d' olivocoltivate in Toscana. Le varietà di olivocoltivate in Italia: 3-16.

7. Botstein, D., White, R., Skolnick, M., Davis, R. (1980). Construction of a genetic-linkage map in man using restriction fragment length polymorphisms. American Journal of Human Genetics 32: 314-331.

8. Carriero, F., Fontanazza, G., Cellini, F., Giorio, G. (2002). Identification of simple sequence repeats (SSRs) in olive (Olea europaea L.). Theoretical and Applied Genetics 104: 301-307.

9. CND, Centre National de Documentation (1955). Catalogue des variétés d'olivier en culture dans les Stations Régionales Horticoles du Maroc (Hiver 1955-56). $\mathrm{N}^{\circ}$ Accession: 60460-56-NO. Service Horticulture, Rabat, Maroc. Pages: 1-5.

10. Cimato, A., Attilio, C. (2003). Conservation, characterization, collection and utilization of the genetic resources in olive. Projet CFC/IOC/03. Pages: 62.

11. Cipriani, G., Marrazzo, M.T., Marconi, R., Cimato, A. (2002). Microsatellite markers isolated in olive (Olea europaea L.) are suitable for individual fingerprinting and reveal polymorphism within ancient cultivars. Theoretical and Applied Genetics 104: 223-228.

12. De La Rosa, R., James, C.M., Tobutt, K.R. (2002). Isolation and characterization of polymorphic microsatellites in olive (Olea europaea L.) and their transferability to other genera in the Oleaceae. Molecular Ecololgy Notes 2(3): 265-267.

13. Dice, L.R. (1945). Measures of the amount of ecologic association between species. Ecology 26: 297-302.

14. Díez, C.M., Imperato, A., Rallo, L., Barranco, D., Trujillo, I. (2012). Worldwide core collection of olive cultivars based on simple sequence repeat and morphological markers. Crop Science 52: 211-221.

15. El Bakkali, A., Haouane, H., Hadidou, A., Oukabli, A., Santoni, S., Udupa, S.M., Van Damme, P., Khadari, B. (2013a). Genetic diversity 
of on-farm selected olive trees in Moroccan traditional olive orchards. Plant Genetic Resources 11(02): 97-105.

16. El Bakkali, A., Haouane, H., Moukhli, A., Costes, E., Van Damme, P., Khadari B. (2013b). Construction of core collections suitable for association mapping to optimize use of Mediterranean olive (Olea europaea L.) genetic resources. PLos One 8(5): e61265.

17. El Bakkali, A., Essalouh, L., Rivallan, R., Mournet, P., Tollon, C., Moukhli, A., Zaher, H., Mekkaoui, A., Hadidou, A., Sikaoui, L., Khadari, B. (2019). Characterization of Worldwide Olive Germplasm Banks of Marrakech (Morocco) and Córdoba (Spain): towards management and use of olive germplasm in breeding programs. Plos One 14(10): e0223716.

18. Escribano, P., Viruel, M.A., Hormaza, J.I. (2007). Molecular Analysis of Genetic Diversity and Geographic Origin within an Ex Situ Germplasm Collection of Cherimoya by Using SSRs. Journal of the American Society for Horticultural Science 132(3): 357-367.

19. Evans, K.M., Patocchi, A., Rezzonico, F., Mathis, F., Durel, C.E., Fernández-Fernández, F., Boudichevskaia, A., Dunemann, F., Stankiewicz-Kosyl, M., Gianfranceschi, L., Komjanc, M., Lateur, M., Madduri, M., Noordijk, Y., Van de Weg, W.E. (2011). Genotyping of pedigreed apple breeding material with a genome-covering set of SSRs: trueness-to-type of cultivars and their parentages. Molecular Breeding 28: 535-547.

20. Haouane, H., El Bakkali, A., Moukhli, A., Tollon, C., Santoni, S., Oukabli, A., El Modafar, C., Khadari, B. (2011). Genetic structure and core collection of the World Olive Germplasm Bank of Marrakech: towards the optimised management and use of Mediterranean olive genetic resources. Genetica 139(9): 1083-1094.

21. Hammer, Ø., Harper, D.A.T., Ryan, P.D. (2001). Past: Paleontological statistics software package for education and data analysis. Palaeontologia Electronica 4(1): 9pp.

22. IOOC. (2016). International Olive Oil Council. Available from http://www.internationaloliveoi.org/.

23. Kaniewski, D., Van Campo, E., Boiy, T., Terral, J.F., Khadari, B., Besnard, G. (2012). Primary domestication and early uses of the emblematic olive tree: palaeobotanical, historical and molecular evidences from the middle east. Biological Reviews 87: 885-899.

24. Khadari, B., Breton, C., Moutier, N., Roger, J.P., Besnard, G., Bervillé, A., Dosba, F. (2003). The use of molecular markers for germplasm management in a French olive collection. Theoretical and Applied Genetics 106: 521-529. 
25. Khadari, B., Charafi, J., Moukhli, A., Ater, M. (2008). Substantial genetic diversity in cultivated Moroccan olive despite a single major variety: a paradoxical situation evidenced by the use of SSR loci. Tree Genetics \& Genomes 4: 213-221.

26. Koehmstedt, A.M., Aradhya, M.K., Soleri, D., Smith, J.L., Polito, V.S. (2011). Molecular characterization of genetic diversity, structure, and differentiation in the olive (Olea europaea L.) germplasm collection of the United States Department of Agriculture. Genetic Resources and Crop Evolution 58(4): 519-531.

27. Muzzalupo, I., Vendramin, G.G., Chiappetta, A. (2014). Genetic Biodiversity of Italian Olives (Olea europaea) Germplasm Analyzed by SSR Markers. Hindawi, The Scientific World Journal v2014. Article ID 296590, 12 pp.

28. Nei, M. (1987). Molecular Evolutionary Genetics. Columbia University Press: New York.

29. Trentacoste, E.R., Puertas, C.M. (2011). Preliminary characterization and morpho-agronomic evaluation of the olive germplasm collection of the Mendoza province (Argentina). Euphytica 177: 99-109.

30. Trujillo, I., Rallo, L., Arus, P. (1995). Identifying olive cultivars by isozyme analysis. Journal of American Society for Horticultural Science 120: 318-324.

31. Trujillo, I., Ojeda, M.A., Urdiroz, N.M., Potter, D., Barranco, D., Rallo, L., Diez, C.M. (2014). Identification of the Worldwide Olive Germplasm Bank of Córdoba (Spain) using SSR and morphological markers. Tree Genetics \& Genomes 10 (1): 141-155.

32. Park, S.D.E. (2001). Microsatellite Toolkit 3.1.1.available at: http://animalgenomics.ucd.ie/sdepark/ms-toolkit/.

33. Perri, E., Lombardo, N., Palopoli, A., Miele, D. (1999). Indaginesul germoplasma di olivo della Sicilia mediante marcatori RAPD. $5^{\circ}$ Convegno Nazionale Biodiversità: 299-304.

34. Perrier, X., Flori, A., Bonnot, F. (2003). Data analysis methods. In: Hamon, P, Seguin, M, Perrier, X,Glaszmann, J C. Ed., Genetic diversity of cultivated tropical plants. Enfield, Science Publishers. Montpellier: 43-76.

35. Petit, R.J., El Mousadik, A., Pons O. (1998). Identifying populations for conservation on the basis of genetic markers. Conservation Biology 12: 844-855.

36. Riaz, S., Tenscher, A.C., Smith, B.P., Daniel, A.N., Walker, M.A. (2008). Use of SSR Markers to Assess Identity, Pedigree, and Diversity of Cultivated Muscadine Grapes. Journal of American Society for Horticultural Science 133(4): 559-568. 
37. Rohlf, F.J. (1998). NTSYS-pc: Numerical taxonomy and multivariate analysis system. Version 2.00. Exeter Software. Setauket, New York.

38. Sarri, V., Baldoni, L., Porceddu, A., Cultrera, N.G.M., Contento, A., Frediani, M., Belaj, A., Trujillo, I., Cionini, P.G. (2006). Microsatellite markers are powerful tools for discriminating among olive cultivars and assigning them to geographically defined populations. Genome 49: 1606-1615.

39. Sefc, K.M., Lopes, M.S., Mendonça, D., Rodrigues Dos Santos, M., Da Cámara Machado, L. (2000). Identification of microsatellites loci in Olive (Olea europaea L.) and their characterization in Italian and Iberian trees. Molecular Ecology 9: 1171-1193.

40. Sokal, R., Michener, C. (1958). A statistical method for evaluating systematic relationships. In: Science bulletin, 38(22), The University of Kansas.

41. Szpiech, Z.A., Jakobsson, M., Rosenberg, N.A. (2008). ADZE: a rarefaction approach for counting alleles private to combinations of populations. Bioinformatics 24: 2498-2504.

42. Xanthopoulou, A., Ganopoulos, I., Koubouris, G., Tsaftaris, A., Sergendani, C., Kalivas, A., Panagiotis, M. (2014). Microsatellite high-resolution melting (SSR-HRM) analysis for genotyping and molecular characterization of an Olea europaea germplasm collection. Plant Genetics Resources 12(3): 273-277. 